\title{
COMMENTARY
}

\section{Why there should be constraints about who performs coronary angioplasty}

The Guidelines for Specialist Training in Cardiology recommended that all trainee cardiologists should gain experience in percutaneous transluminal coronary angioplasty (PTCA) and that those pursuing a career in interventional cardiology should perform 100 procedures during their final period of training. ${ }^{1}$ Now the Guidelines for Training and Continuing Competence, prepared jointly by the British Cardiac Society and the British Cardiovascular Intervention Society recommend that trained cardiologists should undertake a minimum of 60 procedures each year in order to maintain their expertise. $^{2}$

These recommendations have been greeted by some as unnecessary constraints on the clinical freedom traditionally enjoyed by hospital consultants. Doubts have been expressed regarding their validity and some have questioned whether they are necessary at all.

\section{Validity}

There is little published data relating procedure volume to complication rate and none that can be universally applied to the many different settings where PTCA is undertaken worldwide. The present suggestions are thus based on professional opinion and judgement rather than scientific data, and widespread consultation has resulted in a number of modifications. The recommendations then are validated through being produced by the profession itself. Surely this is preferable to external regulation?

\section{Are guidelines necessary?}

If external regulation is to be avoided, the profession must be seen to be acting responsibly and control its own affairs. Purchasing authorities speak of accrediting centres, and perhaps even individuals, for particular procedures as part of their role of commissioning health care, and already they expect provision of data from audit.
There are analogies here with other specialties. Concern over outcomes in the treatment of malignant disease has given rise to the Calman recommendations for cancer units where subspecialisation within the surgical specialties is given great emphasis. Public concerns about outcomes for some relatively new interventional procedures (for example, some laparoscopic procedures) has caused the NHS Executive, in collaboration with the Conference of Colleges, to set up a Safety and Efficacy Register. While it is not expected that the administrators of this register will wish to monitor conventional PTCA, it is interesting to speculate whether the use of this procedure would have developed in its present somewhat haphazard way if it had been subject to closer regulation and scrutiny.

\section{Subspecialisation}

As the specialty of cardiology develops, some subspecialisation is inevitable, particularly if staffing levels improve. No longer can a single individual be expert in the intricacies of PTCA, including stenting and intravascular ultrasound, and expect to be similarly expert in electrophysiology, pacing, and echocardiography as well as general cardiology. It is quite clear that in the face of a rising tide of consumerism in health care, specialists will no longer be able to be Jack of all trades yet master of none.

The guidelines ${ }^{2}$ should be welcomed. Adherence to them will protect the individual, hopefully the patient as well as the cardiologist.

Department of Cardiology,

ROGER BOYLE York District Hospital

1 Hall RJC, Boyle RM, Webb-Peploe M, Chamberlain D, Parker DJ. Guidelines for specialist training in cardiology. Br Heart $\mathcal{f} 1995 ; 73$ (suppl 1):1-24.

2 British Cardiac Society and British Cardiovascular Intervention Society working group on interventional cardiology. Planning for coronary angioplasty: guidelines for training and continuing competence. Heart 1996;75:419-26. 